Таким образом, ценовая политика определила ООО «Агро Комплект» наиболее конкурентоспособным предприятием.

$$
* * *
$$

1. Официальный сайт АО «Радиозавод»-2020. - URL: https://penza-radiozavod.ru/

2. Официальный сайт AO «Белинсксельмаш» - 2021. - URL: https://elvorti.ru/

3. Официальный сайт OОO «Агро Комплект» - 2020. - URL: https://www.posevnaya.ru/

4. АГРОПРОДМАШ - 2021 [Электронный pecypc]. - Режим доступа: https://www.agroprodmashexpo.ru/ru/ui/17157/

5. Шеравнер В.М. Анализ применения ФСА на предприятиях Ростовской области // Пространство экономики. 2006. №1. C.157-160.

6. Жегера К.В., Самигулина Е.А. Оценка конкурентоспособности предприятия $3 \mathrm{AO}$ «Пензенская кондитерская фабрика» с использованием ФСА-анализа // Е-Scio. 2021. №3 (54). С.545-551.

\title{
Киктева П.А. \\ Конкретные случаи неуспеха функционирования особых экономических зон и выявление недостатков их проектирования
}

Российская академия народного хозяйства и государственной службы при Президенте РФ (Россия, Воронеж)

doi: 10.18411/trnio-11-2021-100

Научный руководитель: Сыроижко В.В.

\section{Аннотация}

В данной статье дано понятие особых экономических зон, описаны причины и преимущества внедрения особых экономических зон, проанализирован опыт провалов отдельных экономических зон на территории Российской Федерации, представлены конкретные случаи неуспеха функционирования особых экономических зон таких как: «Долина Алтая», «Новая Анапа», «Куршская коса», «Остров Русских», «Мурманск», «Байкальская Гавань», «Ульяновск», «Моглино», на основе чего выявлены недостатки их проектирования, дана характеристика недостатков, а также представлены возможные пути решения существующих проектных проблем.

Ключевые слова: особая экономическая зона, виды особых экономических зон, недостатки функционирования особых экономических зон, функционирующая особая экономическая зона, прекратившая свое существование особая экономическая зона.

\section{Abstract}

This article gives the concept of special economic zones, describes the reasons and advantages of introducing special economic zones, analyzes the functioning of some economic zones on the territory of the Russian Federation, presents specific cases of failure of the functioning of special economic zones such as: "Altai Valley", "New Anapa", "Curonian Spit", "Russian Island", "Murmansk", "Baikalskaya Gavan", "Ulyanovsk", "Moglino", on the basis of which the shortcomings of their functioning were revealed.

Keywords: a special economic zone, types of special economic zones, shortcomings in the functioning of special economic zones, a functioning special economic zone, a special economic zone that has ceased to exist.

Для успешного ведения экономической деятельности в условиях современной рыночной отечественной экономики следует использовать различные инструментарии: льготное налогообложение и кредитование, государственные гарантии под внешнее финансирование предприятия, «пакет» льгот и привилегий инвесторам, поддержка государства российской продукции на мировом рынке. Это основные инструментарии особых экономических зон. Существование особых экономических зон благоприятно воздействует на развитие отраслевого народного хозяйства. Государство стремится повысить 
инвестиционную привлекательность рынка, поэтому занимается защитой отечественных производителей, повышением конкурентоспособности, а также улучшением условий для инвестиционной деятельности. В таком случае без особых экономических зон не обойтись.

Существование ОЭЗ имеет ряд преимуществ в финансово-правовой и административно-правовой сферах, что позволяет развивать отдельно взятые регионы: стимулировать производство и экспорт, повышать уровень занятого населения, расширять замещение импортных товаров.

Федеральный закон от 22.07.2005 г. №116-Ф3 «Об особых экономических зонах в Российской Федерации» сейчас является необходимой нормативной базой функционирования ОЭЗ. До 2005 года регулирование ОЭЗ находилось на недостаточно высоком уровне. В законодательстве ОЭЗ предусматривается особый механизм осуществления таможенных процессов, регулирования имущественных отношений, деятельности банков, отношений по поводу залогов.

Существует несколько видов особых экономических зон в мировой экономике. Их предназначение различно: увеличение зарубежных инвестиций, мотивация ориентирования предприятий на внутренний рынок, разработка и внедрение инновационных технологий. В соответствии с этим есть различные типы особых экономических зон: производственные, торговые, технико-внедренческие, комплексные.

Благодаря особому таможенному режиму увеличивается товарооборот, привлекаются инвесторы, что благоприятно влияет на скорость экономического роста. Это повлекло за собой широкое распространение создания ОЭЗ в мировой экономике.

Федеральный закон №116-Ф3 «Об особых экономических зонах в Российской Федерации» гласит, что «особая экономическая зона - часть территории Российской Федерации, которая определяется Правительством Российской Федерации и на которой действует особый режим осуществления предпринимательской деятельности, а также может применяться таможенная процедура свободной таможенной зоны». Особые экономические зоны отличаются тем, что на их территории действуют определенные меры, которые облегчают ведение предпринимательской деятельности, а именно льготные условия для существования организации. Они создаются государством для стимулирования регионов [1].

По мнению С. Г. Пьянковой, условия для предпринимательской деятельности выгодные, поэтому посредством образования ОЭЗ привлекаются инвестиции, увеличивается товарооборот, повышается конкурентоспособность и как следствие экспорт, понимается импорт, развивается рынок в соответствии с меняющимися запросами клиентов и научнотехническим прогрессом. Привлечение инвестиций необходимо. Это помогает стабильному развитию региона. Валовый региональный продукт является основой для оценки текущей экономической ситуации и прогнозирования дальнейших изменений. Совершенствование продукции, согласно потребностям клиентов, влечет за собой получения более конкурентоспособного товара, который готов для выхода на мировой рынок, для привлечения иностранных инвесторов, которые станут вкладываться в развитие зарекомендовавшего себя продукта, что положительно повлияет на уровень экспорта и увеличение замещения импортной продукции. Также именно в особых экономических зонах в полной мере проявляется партнерство бизнеса и государства, которое содействует планированию, продвижению и реализации производства. Вследствие функционирования ОЭЗ появляются новые рабочие места, а соответственно снижается уровень безработицы. Благодаря налоговым льготам теневой сектор экономики сокращается, а государственный бюджет увеличивается [2].

О.В. Кузнецова говорит о том, что нужно внедрять более корректные методики для совершенствования оценки работы ОЭЗ. Для этого следует брать во внимание особенности географического расположения ОЭЗ и временной отрезок существования ОЭЗ [3].

А.В. Евстюнина и В.А. Осипов сравнивают условия деятельности инвесторов в индустриальных парках, ОЭЗ, а также территорий опережающего экономического развития [4]. 
Согласно данным следующей таблицы, из восьми туристско-рекреационных ОЭЗ сейчас функционируют только четыре. ОЭЗ, прекратившие свое существование продержались от 3 до 9 лет. Разберем по очереди провал четырех проектов.

ОЭЗ «Долина Алтая» была создана в 2007 году. Должна была эта ОЭЗ располагаться в 25 км от Горно-Алтайска (регионального центра). Планировалось разместить искусственное озеро с тремя искусственно созданными островами. Вокруг должны были располагаться сооружения, предназначенных для отдыха и развлечений. Клиентами должны быть любители активного отдыха, а за год предполагалось около 100-120 тыс. посетителей.

Таблицุа 1

Особые экономические зоны России

\begin{tabular}{|c|c|c|c|c|}
\hline № & Название & Субъект РФ & $\begin{array}{c}\text { Создана } \\
\text { Постановлением } \\
\text { Правительства РФ }\end{array}$ & $\begin{array}{c}\text { Прекращено } \\
\text { существование в } \\
\text { связи с изданием } \\
\text { Постановления } \\
\text { Правительства }\end{array}$ \\
\hline \multicolumn{5}{|c|}{ ОЭЗ ППТ } \\
\hline 1 & «Липецк»» & Липеикая область & $\begin{array}{c}\text { om } 21.12 .2005 \\
\text { №782 }\end{array}$ & \\
\hline 2 & «Алабуга» & Республика Татарстан & $\begin{array}{c}\text { om } 21.12 .2005 \\
\text { №784 }\end{array}$ & \\
\hline 3 & «Тольятти»» & Самарская область & $\begin{array}{c}\text { om } 12.08 .2010 \\
\text { №621 }\end{array}$ & \\
\hline 4 & «Тттановая долина» & Свердловская область & $\begin{array}{c}\text { om } 16.12 .2010 \\
\text { №1032 } \\
\end{array}$ & \\
\hline 5 & «Моглино» & Псковская область & $\begin{array}{c}\text { om 19.07.2012 } \\
\text { №729 }\end{array}$ & \\
\hline 6 & «Людиново»(«Калуга») & Калужская область & & \\
\hline 7 & «Владивосток» & Приморский край & $\begin{array}{c}\text { om } 18.08 .2014 \\
\text { №822 }\end{array}$ & $\begin{array}{c}\text { om } 06.12 .2017 \\
\text { №1477 }\end{array}$ \\
\hline 8 & «Лотос» & Астраханская область & $\begin{array}{c}\text { om } 18.11 .2014 \\
\text { №1214 }\end{array}$ & \\
\hline 9 & «Ступино Квадрат» & Московская область & $\begin{array}{c}\text { om } 08.08 .2015 \\
\text { №826 } \\
\end{array}$ & \\
\hline 10 & «Узловая» & Тульская область & $\begin{array}{c}\text { om } 14.04 .2016 \\
\text { №302 } \\
\end{array}$ & \\
\hline \multicolumn{5}{|c|}{ ОЭЗ TBT } \\
\hline 1 & $\begin{array}{c}\text { «Зеленоград» } \\
\text { («Технополис } \\
\text { «Москва») } \\
\end{array}$ & Город Москва & om 21.12.2005 №77 & \\
\hline 2 & «Санкт-Петербург» & Город Санкт-Петербург & $\begin{array}{c}\text { om } 21.12 .2005 \\
\text { №780 } \\
\end{array}$ & \\
\hline 3 & «Дубна» & Московская область & $\begin{array}{c}\text { om } 21.12 .2005 \\
\text { №781 }\end{array}$ & \\
\hline 4 & «Томск» & Томская область & $\begin{array}{c}\text { om } 21.12 .2005 \\
\text { №783 }\end{array}$ & \\
\hline 5 & «Иннополис» & Республика Татарстан & $\begin{array}{c}\text { om } 01.11 .2012 \\
\text { №1131 }\end{array}$ & \\
\hline 6 & «Исток» & Московская область & $\begin{array}{c}\text { om } 31.12 .2015 \\
\text { №1538 }\end{array}$ & \\
\hline \multicolumn{5}{|c|}{ OЭЗ TPT } \\
\hline 1 & «Долина Алтая» & Республика Алтай & om 03.02.2007 №67 & $\begin{array}{c}\text { om } 28.09 .2016 \\
\text { №978 }\end{array}$ \\
\hline 2 & «Байкальская гавань» & Республика Бурятия & om 03.02.2007 №68 & \\
\hline 3 & «Бирюзовая Катунь» & Алтайский край & om 03.02.2007 №69 & \\
\hline 4 & «Новая Анапа» & Краснодарский край & om 03.02.2007 №70 & $\begin{array}{c}\text { om } 24.09 .2010 \\
\text { №752 }\end{array}$ \\
\hline 5 & «Ворота Байкала» & Иркутская область & om 03.02.2007 №72 & \\
\hline 6 & «Куриская коса» & $\begin{array}{c}\text { Калининградская } \\
\text { область }\end{array}$ & om 03.02.2007 №73 & $\begin{array}{c}\text { om } 18.12 .2012 \\
\text { №1330 }\end{array}$ \\
\hline
\end{tabular}




\begin{tabular}{|c|c|c|c|c|}
\hline 7 & «Остров Русский» & Приморский край & $\begin{array}{c}\text { om } 31.03 .2010 \\
\text { №201 }\end{array}$ & $\begin{array}{c}\text { om } 28.09 .2016 \\
\text { №978 }\end{array}$ \\
\hline 8 & «Долина Алтая» & Республика Алтай & om 03.02.2007 №67 & $\begin{array}{c}\text { om } 28.09 .2016 \\
\text { №978 }\end{array}$ \\
\hline \multicolumn{5}{|c|}{ Портовые ОЭЗ } \\
\hline 1 & «Ульяновск» & Ульяновская область & $\begin{array}{c}\text { om } 30.12 .2009 \\
\text { №1163 } \\
\end{array}$ & \\
\hline 2 & «Советская Гавань» & Хабаровский край & $\begin{array}{c}\text { om } 31.12 .2009 \\
\text { №1185 }\end{array}$ & $\begin{array}{c}\text { om } 28.09 .2016 \\
\text { №978 }\end{array}$ \\
\hline 3 & «Мурманск» & Мурманская область & $\begin{array}{c}\text { om } 12.10 .2010 \\
\text { №800 }\end{array}$ & $\begin{array}{c}\text { om } 28.09 .2016 \\
\text { №978 }\end{array}$ \\
\hline
\end{tabular}

Над проектом трудились немецкие специалисты. Строительство началось только спустя 2 года. Котлован обошелся 1,1 млрд. рублей размером 400м на 1,5км. Его глубина по плану составляла 5м. Также началось строительство трех коттеджей и одного комплекса гостиничного назначения. Только в 2012 году стали заполнять водой котлован. Проблема заключалась в том, что дно котлована покрыли полиэтиленовой пленкой, чтобы вода не утекала. В итоге пленка не выдержала водного массива, и через прохудившееся дно вода стала утекать. Было еще несколько попыток заполнить озеро, но так ничего и не вышло. В ОЭЗ было вложено 8 млрд рублей из госбюджета и 15 млрд рублей частных лиц. Руководство требовало возмещение ущерба от строителей, но они отказались выплачивать [5].

«Новая Анапа» прекратило свое существование одной из первых 24 сентября 2010 года, причиной чего послужило отсутствие инвестиционных соглашений в течение трех лет. На строительство государство выделило 170 млн рублей из госбюджета, хотя планировалось 500-700 млн. Также оказалось, что часть территории находится в частной собственности.

Калининградская ОЭЗ «Куршская коса» прекратила свое существование в 2012 году 18 декабря. Планировали разместить ОЭЗ на территории заповедника. Создана она была 3 февраля 2007 года. В 2009 году государство приостановило финансирование ОЭЗ. Было вложено 6 млрд рублей. Однако экологи раскритиковали данный проект. Дело в том, что на данной территории располагались песчаные дюны, а вместе с ними редкие растения. Там же еще располагалась единственная орнитологическая станция. К тому же Куршская коса была внесена в список ЮНЕСКО. На ОЭЗ хотели сделать 4 туристско-рекреационных участка. Но Правительство РФ раньше срока решило расформировать ОЭЗ.

Следующей закрытой ОЭЗ считается «Остров Русский» в Приморском крае. В данном случае причиной досрочного закрытия послужило отсутствие соглашений в течение 3 лет с момента создания ОЭЗ, также частью территории владело Минобороны. ОЭЗ федеральными средствами не финансировалось, только региональными и муниципальными, а также внебюджетными инвестициями. Однако для инвесторов «Остров Русский» привлекательным не показался.

Проанализируем данную информацию. «Долина Алтая» прекратило существование из-за неправильного строительства, «Новая Анапа» и «Остров Русских» - из-за отсутствия заключения соглашений в течение 3 лет с момента создания, а строительство инфраструктуры «Куршской косы» остановилось через 2 года после создания ОЭЗ, инвесторов и резидентов привлечь не получилось. То есть почти с половиной ОЭЗ туристско-рекреационного типа соглашения не подписывают. Также существует проблема определения собственности земель ОЭЗ. Часть из них находится либо в частной собственности, либо (в конкретном случае) в собственности Министерства обороны РФ. Также существуют проблемы с государственным финансированием ОЭЗ [5].

Две ОЭЗ портового типа из трех прекратили свое существование, а именно «Советская Гавань» и «Мурманск». Обе ОЭЗ закрыли в 2016 году 28 сентября. Просуществовали они 6-7 лет. Она создавалась с целью транспортировки товаров нескольких компаний. Однако Счетная палата провозгласила ОЭЗ неэффективной. 
Государственные вложения размером 2,96 млрд. рублей так и не реализовались. Управляющая компания региона сформирована была в 2015 году, передача полномочий осуществилась только в 2016 году. Правительство ссылалось опять на Федеральный закон №116, который гласит, что ОЭЗ прекращает свое существование, если за три года не зарегистрировано ни одного резидента. На оформление земельно-имущественных отношений и разработку плана обустройства ОЭЗ «Мурманск» было выделено 56,05 млн рублей. Однако резидентов привлечь так и не получилось [2].

По этой же причине была ликвидирована ОЭЗ «Владивосток», которая создавалась с целью производства двигателей Региональными властями было выделено 100 млн рублей на создание инфраструктуры. А в конце 2016 года из федерального бюджета ОЭЗ получила 835,7 млн рублей.

Счетная палата в 2016 году предоставила информацию о том, что ОЭЗ оказались мало эффективным инструментом развития экономики, так как власть не устанавливает всеобщий стандарт создания ОЭЗ, не принимает достаточное количество мер для обеспечения успешного их функционирования. Сергей Агапцов считает, что желаемого результата достигнуть не удалось. В начале 2018 года все вложения на строительство инфраструктуры составили 491,9 млрд рублей. Около половины шли из федерального бюджета. Счетная палата обвинила исполнительную власть и Минэкономразвития в невыполнении своих обязательств по управлению ОЭЗ, а также неправильной организации строительства инфраструктуры [6].

Действительно, создание ОЭЗ нельзя посчитать успешным инвестированием в экономику страны. Многие ОЭЗ прекратили свое существование по причине элементарной халатности: техническая недоработка покрытия для создания водоема или же отсутствие учета формы собственности земельных участков. Так как случаи создания неудачного проекта ОЭЗ частые, необходимо урегулировать данный вопрос разработкой и утверждением единого стандарта проектирования, реализации и эксплуатации ОЭЗ с учетом типов ОЭЗ.

«Бирюзовую Катунь», «Байкальскую Гавань», «Ульяновск», «Моглино» находятся в числе 10 неэффективных ОЭЗ. Критерием оценки эффективности считается отношение вложений из государственного бюджета и вложений частных инвесторов. На них государство потратило 55,1 млрд рублей, а привлеченные инвестиции составили 7,6 млрд рублей [4].

По мнению Счетной палаты, существуют следующие недостатки функционирования:

1) рабочие места создавать дорого;

2) планы функционирования ОЭЗ выполнены ненадлежащим образом;

3) затянутый процесс строительства инфраструктуры, что отпугивает инвесторов;

4) плохо обоснованы и проанализированы федеральные, региональные и муниципальные вложения;

5) большие объемы неиспользованных государственных средств;

6) малая выручка резидентов;

7) правовая база ненадлежащего уровня;

После проверок Счетной палаты прекратили свое существование 2 портовые ОЭЗ и 6 туристско-рекреационных ОЭЗ. Также был подписан мораторий на создание ОЭЗ в течение 2 лет (2017 и 2018 годы) [5].

Сейчас в России наступила вторая волна развития ОЭЗ. Однако недостатки следует отследить, чтобы исправить ошибки первой волны в дальнейшем. Таким образом, О.А. Чепинога, М.В. Солодков и А.Э. Семёнова пишут о следующих недостатках:

1) ненадлежащее законодательство;

2) в России проверяют не так, как в мире;

3) критерии оценки эффективности ОЭЗ не до конца утверждены;

4) ОЭЗ находятся далеко от крупных населенных пунктов;

5) государство контролирует большую часть работы ОЭЗ; 
6) плохой инвестиционный климат в РФ;

7) нет систематизации результатов деятельности [7].

В ходе исследования стало известно, что создание и функционирование ОЭЗ является малоэффективным инструментом привлечения инвестиций и развития региона. На практике можно столкнуться с халатностью работников, что повлечет за собой огромные убытки резидентов и нереализованные государственные средства, как, например, произошло с ОЭЗ «Долины Алтая». Для благоприятного развития ОЭЗ необходимо улучшать инвестиционный климат во всей стране, а не на ее отдельных территориях. Необходимо разработать единый стандарт на территории РФ для проектирования, реализации и эксплуатации ОЭЗ. При этом должны учитываться различные типы ОЭЗ. Недостатки в законодательстве влекут за собой недостатки в проектировании ОЭЗ, что является ключевым фактором неуспеха ее дальнейшего функционирования. Также существует проблема привлечения инвесторов. Условия инвестирования должны быть более выгодные, а информация о проектах более доступной.

$$
* * *
$$

1. Федеральный закон "Об особых экономических зонах в Российской Федерации": [принят 22.07.2005] № 116Ф3 (ред. от 18.07.2017). - $\quad$ оЭлектронный ресурс]. http://www.consultant.ru/document/cons_doc_LAW_54599/

2. Пьянкова С., Исследование особых экономических зон в системе обеспечения экономической безопасности субъекта Российской Федерации / С. Пьянкова, Косцова А., Международный журнал прикладных и фундаментальных исследований. - 2019. - № 7. - С. 157-161.

3. Кузнецова О.В. Особые экономические зоны: эффективны или нет? / Кузнецова О.В. // Пространственная экономика. - 2016. - №4. - С. 129-152.

4. Евстюнина А.В., Анализ практики создания и функционирования инфраструктурных инвестиционных проектов / Евстюнина А.В., Осипов В.А., Российский экономический интернет-журнал. - 2018. - №2. - С. 28.

5. Осипов В.А. Особые экономические зоны как ресурс интенсификации экономического развития: российский и белорусский опыт / В.А. Осипов // Отходы и ресурсы. - 2018. - № 4. - С. 2.

6. Ученые записки Алтайского филиала Российской академии народного хозяйства и государственной службы при Президенте Российской Федерации: сборник статей / под ред. Панарина И. - Алтайский филиал РАНХиГС, Барнаул, 2018. - 155-159 с.

7. Чепинога О.А., Проблемы функционирования и перспективы развития особых экономических зон в России / Чепинога О.А., Солодков М.В., Семёнова А.Э., Baikal Research Journal. - 2017. - №3.

\section{Киктева П.А. \\ Предпосылки внедрения и анализ применения налога на профессиональный доход на территории Российской Федерации}

Российская академия народного хозяйства и государственной службы при Президенте РФ (Россия, Воронеж)

doi: 10.18411/trnio-11-2021-101

Научный руководитель: Сырочжко В.В.

\section{Аннотация}

В данной статье описаны предпосылки утверждения Федерального закона «О проведении эксперимента по установлению специального налогового режима «Налог на профессиональный доход»», дана краткая информационная справка о налоге на профессиональный доход, приведены статистические данные Федеральной Налоговой службы о представленных физическими лицами в налоговые органы уведомлениях об осуществлении деятельности, которую можно классифицировать как самозанятость, также проведен анализ применения налога на профессиональный доход и определены перспективы развития налогообложения по данному вопросу.

Ключевые слова: налог, самозанятые граждане, налог на профессиональный доход, эксперимент по установлению налога, неформальная экономическая деятельность. 